\title{
A new approach to modeling the behavior of frozen soils
}

\author{
Ali Nassr \\ Department of Engineering, University of Exeter, North Park Road, Exeter, EX4 4QF \\ Email address: adnn201@exeter.ac.uk
}

\section{Mahzad Esmaeili-Falak}

Department of Civil Engineering, Faculty of Geotechnical Engineering, University of Tabriz, 29 Bahman Blvd, Tabriz

Email address: mahzad.ef@tabrizu.ac.ir

\section{Hooshang Katebi}

Department of Civil Engineering, Faculty of Geotechnical Engineering, University of Tabriz, 29 Bahman Blvd, Tabriz

Email address: katebi@tabrizu.ac.ir

\author{
Akbar Javadi (Corresponding author) \\ Department of Engineering, University of Exeter, North Park Road, Exeter, EX4 4QF \\ Email address: A.A. Javadi@exeter.ac.uk \\ Tel: +44 1392723640
}




\section{A new approach to modeling the behavior of frozen soils}

Ali Nassr, Mahzad Esmaeili-Falak, Hooshang Katebi, Akbar Javadi

29

30

31

32

\section{Abstract}

In this paper a new approach is presented for modeling the behavior of frozen soils. A datamining technique, Evolutionary Polynomial Regression (EPR), is used for modeling the thermo-mechanical behavior of frozen soils including the effects of confining pressure, strain rate and temperature. EPR enables to create explicit and well-structured equations representing the mechanical and thermal behavior of frozen soil using experimental data.

A comprehensive set of triaxial tests were carried out on samples of a frozen soil and the data were used for training and verification of the EPR model. The developed EPR model was also used to simulate the entire stress-strain curve of triaxial tests, the data for which were not used during the training of the EPR model. The results of the EPR model predictions were compared with the actual data and it was shown that the proposed methodology can extract and reproduce the behavior of the frozen soil with a very high accuracy. It was also shown that the EPR model is able to accurately generalize the predictions to unseen cases. A sensitivity analysis revealed that the model developed from raw experimental data is able to extract and effectively represent the underlying mechanics of the behavior of frozen soils. The proposed methodology presents a unified approach to modeling of materials that can also help the user gain a deeper insight into the behavior of the materials. The main advantages of the proposed technique in modeling the complex behavior of frozen soil have been highlighted.

Key words: frozen soils, soil modeling, triaxial test, data mining 


\section{Introduction}

51 Artificial ground freezing (AGF) has been extensively used in underground engineering. It has negligible effects on the volume change of ground, adjacent buildings, groundwater, surrounding soil and environment (Chamberlain 1981). Accurate determination of the shearing behavior of frozen soils under different conditions and stress paths plays an important role in the geotechnical construction projects such as open excavations, underground subway stations and tunnels. Improper determination of the behavior of frozen soils could have disastrous consequences as it could lead to underestimation of the allowable shear strength under loading conditions of a particular application.

In AGF, artificial withdrawal of heat temporarily freezes the in-situ soil which leads to stabilization of the soil mass such that the closed frozen bodies are watertight (Ziegler et al. 2013). One of the main benefits of AGF is that frozen bodies can be produced in all soil conditions such as heterogeneous, soft and loose soils. AGF is an eco-friendly method, because during implementation, there is no environmental impact on the soil and groundwater (Harris, 1995). It should be noted that AGF in geotechnical engineering should not be mistaken for natural earth freezing or permafrost freeze-thaw cycles (Wang et al. 2016). AGF is the deliberate freezing of pore water of soil which leads to increase in shear strength and reduction in permeability. In the last decade, AGF has been used as a method for temporary stabilization and hydraulic sealing in different areas (Johansson, 2009). The mechanical behavior of unfrozen soils has been extensively investigated by many researchers, however, there has been more limited research on the behavior of frozen soils. Frozen soils exhibit higher strength under loading compared with unfrozen soils (Czurda \& Hohmann 1997). They also show similarity with ice behavior in terms of a time dependent creep and their frictional properties like unfrozen phase (Ma and Chang 2002). Frozen soil can be considered as a complex multiphase material 
consisting of soil particles, frozen water, unfrozen water and air (Lackner et al., 2005). Some researchers have studied the mechanical behavior of frozen soils through laboratory experiments (Yang et al. 2010, Esmaeili-falak et al. 2017, Xu et al. 2017). AGF was first applied on a mine shaft project near Swansea, South Wales, in 1862 (Li et al., 2006).

Zhang et al. (2007) carried out extensive experimental work on frozen sand under different confining pressures (CPs) using a triaxial apparatus. The results showed that volume of frozen soils changed with temperature, confining pressure and soil type. It was also concluded that during shearing, the average cross-sectional area increased nonlinearly with increasing axial strain and confining pressure. Xu et al. (2011) investigated the behavior of ice saturated frozen soil through a series of triaxial compression tests. The results showed that with increasing $\mathrm{CP}$, the shear strength changed during three distinct phases. They used improved Duncan-Chang nonlinear model to analyze the stress-strain behavior. The results showed that the softening behavior could be accurately described using this model.

In addition to the stress-strain behavior of frozen soils, the thermal gradient plays an important role in stability analysis of geotechnical projects involving artificial ground freezing.

Zhao et al., (2013a) carried out a series of triaxial compression tests on a clay soil frozen with non-uniform temperature, by using two methods under different CPs and thermal gradients: (i) with $\mathrm{K}_{0}$ consolidation (where the lateral strains were constrained) $\left(\mathrm{K}_{0} \mathrm{DCGF}\right)$, and (ii) without $\mathrm{K}_{0}$ consolidation (GFC). The results showed that the compressive strength of frozen clay increases with increasing $\mathrm{CP}$ in the $\mathrm{K}_{0} \mathrm{DCGF}$ test, however, it decreases with increasing $\mathrm{CP}$ in the GFC test. It was also shown that at a constant CP, the compressive strength of frozen clay decreases with increasing thermal gradient in both $\mathrm{K}_{0} \mathrm{DCGF}$ and GFC tests. In the $\mathrm{K}_{0} \mathrm{DCGF}$ test, the interaction between soil particles and pore ice significantly influences the strength of the frozen clay. 
Zhao et al. (2013b) conducted a further set of uniaxial compression tests applying different average temperatures and thermal gradients on a frozen saturated clay. The results showed that the uniaxial stress-strain curve of the frozen clay exhibit a linear elastic with strain hardening behavior due to the effect of thermal gradient. It was also shown that decrease in average temperature and thermal gradient increases the hardening behavior and uniaxial compressive strength; but the elastic modulus varies slightly as the thermal gradient increases. Yang et al. (2016) investigated the behavior of a frozen silt in a series of experimental tests under various CPs and at temperatures between -2 to $-8{ }^{\circ} \mathrm{C}$. The output of this work showed that the mechanical properties of frozen silt were highly influenced by $\mathrm{CP}$ and temperature. The stress-strain curves presented strain softening behavior through the shearing stage particularly at low CPs. However, by increasing CP, the strain softening decreased; and the curves moved towards strain hardening at high CPs.

Over the last few years, several attempts have been made to develop constitutive and numerical models for frozen soils. Yang et al. (2010) presented a constitutive model based on experimental results using the Lade-Duncan strength function in $\pi$-plane and in p-q-plane together. In this research, an elasto-plastic model was proposed to simulate the non-linear behavior of frozen silt. This constitutive model employed yield surfaces with non-associated flow rule for compressive and shear behavior. The actual and model predicted results were compared showing a close agreement under low and high confinement.

Lai et al. (2016) presented a constitutive model for frozen saline soil based on a series of triaxial compression tests. The developed model involved the effect of salt content on frozen soil properties. They showed that the developed model can represent the mechanical behavior of the soil with both straight and curved critical state lines as well as predicting the deformation of such soils. 
123 Rotta Loria et al., (2017) introduced a nonlinear elastic plastic model with associated flow rule,

124 which is able to simulate the non-linear behavior of frozen silt. The validity of the developed model was verified using data obtained through triaxial tests from the literature, and it was shown that it can reasonably predict the nonlinearity of the behavior of frozen silt at low and

127 high confinement.

$128 \mathrm{Xu}$ et al. (2017) proposed an elasto-plastic model to describe the behavior of frozen Helin Loess, considering the effects of strain rate and temperature. The experimental results revealed that the stress-strain curves of saturated frozen Helin loess exhibited strain-softening behavior due to the temperature and strain rate conditions applied in the tests. The model parameters were identified by fitting the experimental data. Comparing the experimental and simulated results showed a close agreement and it was shown that the constitutive model can predict the behavior of frozen Helin loess with reasonable accuracy.

Recently, with the developments in the computational field (software and hardware) some researchers (e.g. Jahed Armaghani et al., 2015; Momeni et al., 2014) have emphasized on the use of soft computing techniques such as the Simple Regression Analysis (SRA), Multiple Regression Analysis (MRA) and Artificial Neural Network (ANN) in geotechnical engineering problems. Data-driven models provide reasonable, quick and rigorous tools for solving wide range of engineering problems, in particular when the relations between independent and dependent parameters are unknown and complex. Furthermore, from the cost view point, these methods are helpful as direct determination of behavior of frozen soils in laboratory is costly. To the authors' knowledge, no previous research has been reported on the application of artificial intelligence techniques to describe the constitutive behavior of frozen soils. the behavior of unfrozen soils and rocks (e.g. Millar, 2008; Monjezi and Rezaei, 2011). 
147 In this paper, a data-mining technique is presented for modeling of the thermo-mechanical 148 behavior of frozen soil including the influences of strain rate, confining pressure, and temperature on the soil behavior. The data mining model used is the evolutionary polynomial regression (EPR), which is considered as a gray box model as it can generate relatively simple mathematical structures to describe the behavior of a system (as opposed to black box models like artificial neural network (ANN) that generates large complex structures (Rezania et al., 2008). A comprehensive set of triaxial tests is conducted on soil samples taken from Line 2 of Tabriz urban railway, Tabriz, East Azerbaijan province, Iran (from $38^{\circ} 04^{\prime} 34.9^{\prime \prime} \mathrm{N}$ and $46^{\circ} 12^{\prime}$ $50.3^{\prime \prime} \mathrm{E}$ to $38^{\circ} 02^{\prime} 30.91^{\prime \prime} \mathrm{N}$ and $46^{\circ} 24^{\prime} 53.9^{\prime \prime} \mathrm{E}$ ) and the data are used to develop and validate the proposed EPR model. This model is developed according to an incremental strategy using six input parameters (temperature, confining pressure, strain rate, axial strain, axial strain increment and devatoric stress) and one output parameter (devatoric stress for next increment). The model is also used to produce the stress-strain curve of triaxial tests.

\section{Triaxial experiments}

Triaxial testing can be used to determine the mechanical behavior of frozen soils. In this research triaxial compression tests have been conducted using standard procedures according to ASTM D4083 (D4083-89, 2016). However, there are some challenges in direct determination of behavior of frozen soils in the laboratory. For example, despite significant developments in hardware, software and methods of laboratory testing of soils under various conditions, preparing the triaxial apparatus for testing of frozen soils is often difficult, as it is an expensive and unconventional geotechnical test. 
171 There are very few institutions with the facilities and capability to carry out experiments on 172 frozen soils (Pimentel and Anagnostou, 2010).

173 Another problem in laboratory simulation of AGF is that, it requires a cold and insulated room 174 with minimal heat transfer (Da Re et al. 2003). Also, the test procedure is very time consuming 175 and expensive (Ziegler et al., 2009). Considering these difficulties, in the present research a triaxial compression test apparatus for frozen soils was designed and fabricated (Fig 1). A comprehensive program of tests was carried out in an insulated cold room in the Department of Civil Engineering at Tabriz University, where the temperature of the room was constantly monitored and controlled.

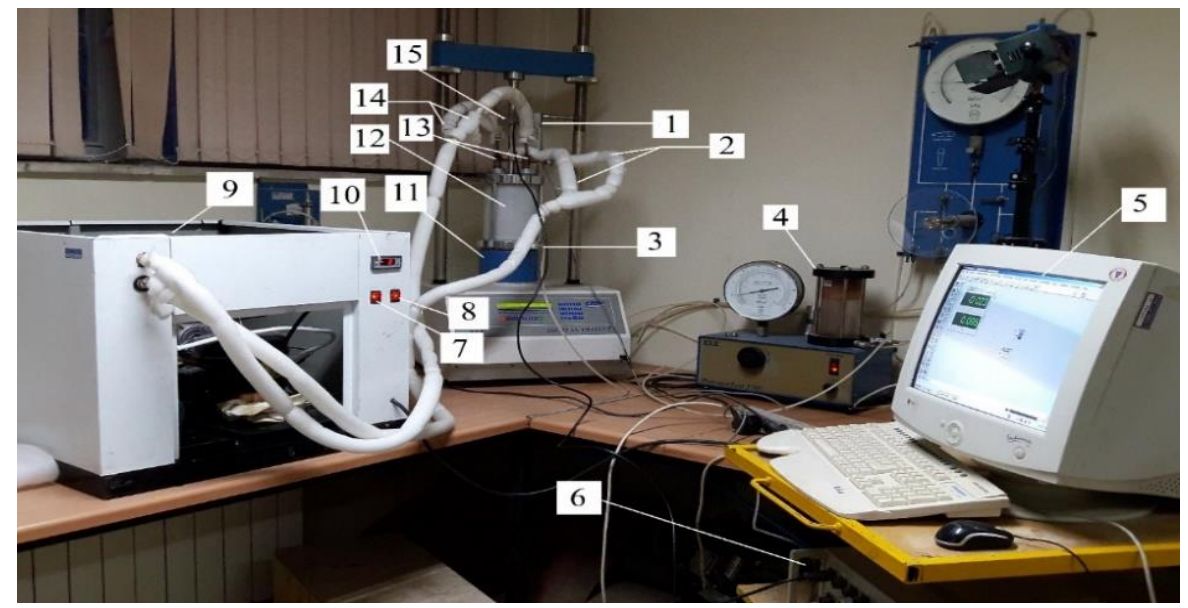

Figure 1. Triaxial compression test apparatus for frozen soils: (1) LVDT, (2) coolant output, (3) confining pressure valve, (4) confining pressure system, (5) computer system, (6) data acquisition, (7) pump power, (8) cooling power, (9) cooling machine, (10) thermostat-thermometer, (11) deviator stress system, (12) triaxial chamber, (13) thermal transducer, (14) coolant input, (15) load cell. 
187 Samples from the borehole core were transported to the geotechnical laboratory of the 188 University of Tabriz to determine the mechanical parameters of the frozen soil under different conditions (confining pressure, strain rate and temperature). Based on some initial tests on the unfrozen soil samples, the soil was classified as poorly graded sand (SP) according to the United Soil Classification System (USCS) with ASTM D2487 (D2487, 2007). The gradation curve of the soil is shown in Fig 2. From triaxial tests on the unfrozen soil samples, the cohesion intercept and the angle of shearing resistance of the soil were determined as 0 and $33^{\circ}$, respectively. The physical properties of the soil are presented in Table 1. As the soil is cohesionless, due to the problems of obtaining identical and repeatable samples and the inevitable disturbance during transportation and testing of the samples, it was decided to prepare remolded soil samples according to the compaction and site conditions in order to ensure reproducibility and comparability of the results.

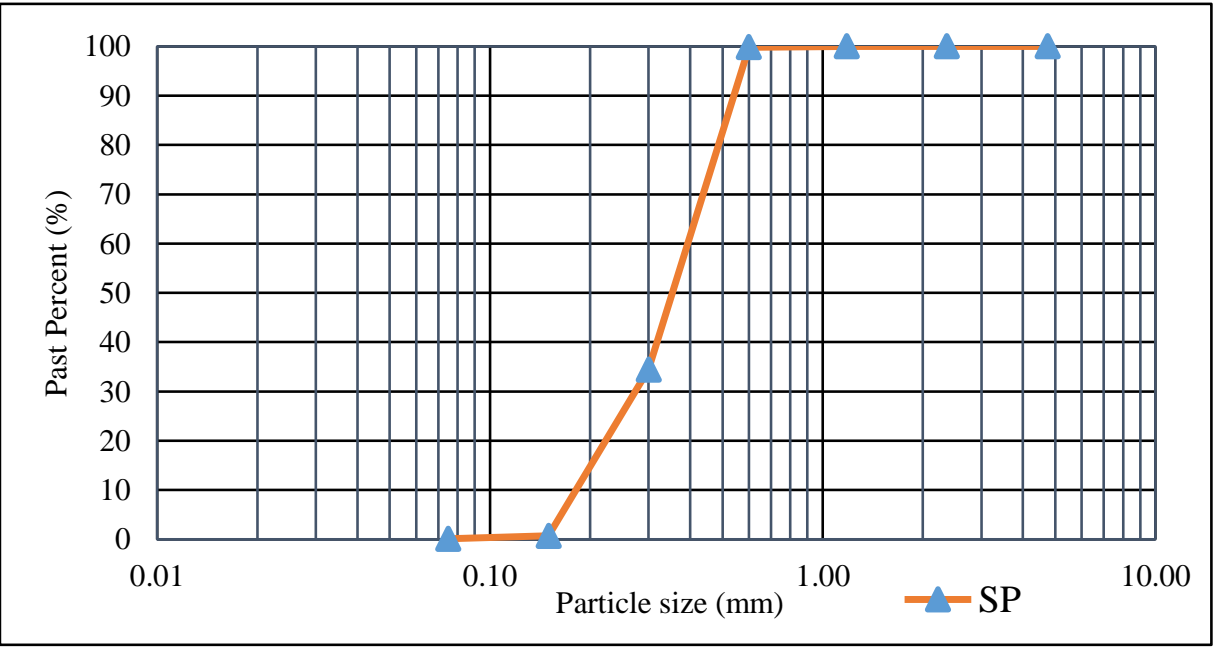


Table 1 Physical properties of SP soil.

\begin{tabular}{ll}
\hline Soil classification & SP \\
\hline Saturated density $\left(\mathrm{Mg} / \mathrm{m}^{3}\right)$ & 1.98 \\
Angle of friction (degree) & 33 \\
Specific gravity $(\mathrm{Gs})$ & 2.635 \\
Gravel $(\%)$ & 0 \\
Sand $(\%)$ & 98.8 \\
Clay and silt $(\%)$ & 1.2 \\
Coefficient of uniformity $(\mathrm{Cu})$ & 2.17 \\
Coefficient of curvature $(\mathrm{Cc})$ & 1.04 \\
\hline
\end{tabular}

205

206 Remolded soil samples with the same void ratio and degree of saturation of ice were used, so

207 that a regular void ratio and saturation of $100 \%$ were considered. The prepared soils were cured in split aluminum molds which were insulated from the bottom and top, so, freezing was propagated in the radial direction in all of the samples (Fig. 3). The freezing process was so rapid that no ice lenses were formed. Five percent of the samples were split before the testing to monitor the absence of ice lenses.

212

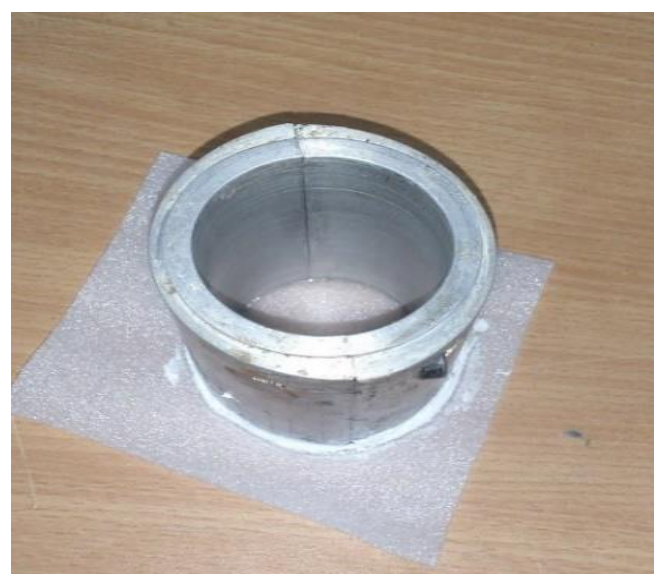

Figure 3. Curing mold used for sample preparation. 
216 After freezing, the specimens showed volumetric expansion in the longitudinal axis from the

217 top and bottom faces. The top and bottom surfaces of the samples were levelled with spiral

218 grinding machine. A total of 82 frozen sandy soil samples were prepared for the laboratory

219 tests. Unconsolidated undrained (UU) triaxial tests were chosen as an appropriate

220 representation of in situ conditions applied on the frozen samples under different conditions of confining pressure, strain rate and temperature. The results showed a strain-softening behavior for all specimens in all the tests.

\section{Evolutionary polynomial regression (EPR)}

EPR is a new hybrid data mining algorithm, based on an evolutionary computational procedure. When applied to material modeling, its target is to find the best polynomial equation representing the behavior of the material in a unified framework (Giustolisi and Savic, 2006). The main advantages of the polynomial structures have been utilized in this algorithm to develop a model in an appropriate mathematical form. The main feature of EPR is to use a genetic algorithm (GA) to find out the more suitable exponents of the polynomial expressions. This gives an efficient search for explicit equations which can represent the behavior of a system and offers more control on the complexity of the structures generated. It also simplifies the computational implementation of the algorithm (Giustolisi and Savic, 2006). The general structure of EPR can be stated as

where $Y$ represents the output ; $a_{j}$ is a constant parameter; $F$ is a function built during the analysis; $X$ is the input variables matrix; $f$ is a function that can be identified by the user (which could include no function, logarithmic, exponential, tangent hyperbolic and secant hyperbolic), 
$255 \quad X=\left[\begin{array}{ccc}X_{11} & X_{12} & X_{1 k} \\ X_{21} & X_{22} & X_{2 k} \\ \ldots & \ldots & \ldots \\ X_{N 1} & X_{N 2} & X_{N K}\end{array}\right]=\left[\begin{array}{lll}X_{1} & X_{2} & X_{3} \ldots \ldots \ldots X_{k}\end{array}\right]$ inputs, $X=\left\langle X_{1} X_{2} \ldots X_{k}\right\rangle$ (Giustolisi and Savic, 2006). matrix form of input variables $(X)$ can be presented as:

where $Y_{N \times 1}(\theta, Z)$ is the vector of $\mathrm{N}$ target values; $\theta_{d \times 1}$ is the vector of $d=m+1$ parameters $a_{j}$, $j=1: m$ and $a_{0} ; Z_{N \times d}$ is a matrix form generated by 1 (unitary vector) for bias $a_{0}$ and $\mathrm{m}$ vectors of variables $Z^{j}$. for a fixed $\mathrm{j}$, variables $Z^{j}$ are a product of the independent predictor vectors of

Generally, EPR consists of two steps to build up a mathematical model. In the first step, a GA is used to search for the best equation form, which is a combination of vectors of independent input parameters, $X_{s}=1: k$, and in the second step, the least square technique is used to find the adjustable parameters $(\theta)$ for every single combination of inputs. A global search procedure is incorporated for the best set of input parameters and the corresponding exponents simultaneously based on a cost function specified by the user (Giustolisi and Savic, 2006). The

256 where the $k^{\text {th }}$ column is the candidate variables for the $j^{\text {th }}$ term in eq. (2), which can be written as: 
$261 Z^{j}$ is the $j^{\text {th }}$ column vector and their members are products of independent inputs variables, ES

262 is a matrix of proposed exponents. The target of algorithm is to find the matrix $\mathrm{ES}_{\mathrm{kxm}}$ of 263 exponents in a range specified by the user.

264 The general framework of the EPR algorithm is shown in Figure 4. More details on the EPR 265 method can be found in Doglioni et al. (2008) and Giustolisi and Savic, (2009, 2006). EPR can 266 work with single or multi-objective optimization in order to represent the best symbolic 267 equation (Giustolisi and Savic, 2009). In this work a multi-objective strategy is utilized to 268 develop the EPR models. The accuracy of the EPR models is calculated based on the coefficient 269 of determination $(C o D)$ as:

271 where $Y_{a}$ is the actual data; $Y_{p}$ is the corresponding predicted data and $N$ is the number of data 272 points on which the $C o D$ is evaluated (Giustolisi and Savic, 2009, 2006). 
Generate initial population of exponent vectors randomly

Figure 4. Flow diagram representing the EPR procedure (Doglioni et al., 2008). 


\section{EPR based material modeling}

302

303

304

305

306

307

308

309

310

311

312

313

314

315

316

317

318

EPR has been successfully applied to a range of engineering applications. It is an effective tool which is able to overcome some of the drawbacks in other types of data mining techniques such as neural network and genetic programing (Javadi et al., 2012; Rezania; et al., 2008). An EPR based model has many advantages in representing the behavior of complex materials. It provides a unified approach to material modelling and can be considered as the shortest path from experiments to numerical modelling as it learns the material behavior from experimental or field data directly without any assumptions (Rezania; et al., 2008). Models developed by EPR provide explicit mathematical equations that give the user a good understanding of the effect of input variables on the predicted output. EPR was first used for environmental modeling by Doglioni et al. (2008). Its application was then extended to various civil engineering problems including geotechnical engineering (Ahangar-Asr et al., 2011; AlangarAsr; and Javadi, 2011; Rezania; et al., 2008). EPR has been used to model the complex behavior of saturated and unsaturated soils with very high accuracy. Results from a number of comparative studies have shown that EPR models outperform ANNs (Ahangar-Asr et al., 2015; Alani and Faramarzi, 2014; Javadi et al., 2012; Rezania; et al., 2008).

\subsection{Training strategy}

Generally, there are two strategies (total stress-strain strategy and incremental stress-strain strategy) that can be used to train EPR to generate a constitutive model representing the material behavior (Faramarzi et al., 2012). In the first strategy, strains are used as input and stresses as output. In the second strategy, the input and output data are used incrementally. In this strategy the input data provide the EPR model with adequate information on the current state of stresses and strains while the output parameter represents the next state of stress 
corresponding to an input strain increment. The selection of an appropriate scheme for training EPR models depends on several factors such as the source of data and the way the data are used to train EPR. In this research the incremental strategy has been utilized for training of the EPR models.

\subsection{Data preparation and EPR model}

Data from a comprehensive set of triaxial experiments on samples of frozen soil are used to train an EPR-based model to predict the stress-strain behavior of the soil. The tests were performed on samples of a sand compacted in the laboratory, under different confining pressures, temperatures and strain rates. The testing program included unconsolidated undrained triaxial (UU) tests where the axial strain was applied increasingly to shear the sample under constant confining pressure. In the experiments, the samples were tested at temperatures ranging between $-0.5^{\circ} \mathrm{C}$ to $-11^{\circ} \mathrm{C}$ and strain rates between 0.1 to $2 \mathrm{~mm} / \mathrm{min}$. The applied confining pressures varied between 0 to $800 \mathrm{kPa}$. The dataset was divided into two groups, the first group ( $80 \%$ of the data) was used for training of the EPR model, while the remaining (20\% of the) data, which was not used in the training stage, was used to validate the prediction capability of the developed EPR model. In general, if a larger portion of data is used for training, the accuracy of the training will improve. Many researchers have used about $80 \%$ of the data for training and $20 \%$ for testing (e.g. Ahangar-Asr et al., 2015; Alangar-Asr; and Javadi, 2011; Rezania; et al., 2008). It was ensured that all parameters in the testing dataset lied between the minimum and maximum values used in the training dataset to avoid extrapolation.

The incremental stress-strain strategy was employed in developing the EPR model. The EPR model has six input variables as shown in Table (2). The input variables of the model are the temperature, confining pressure, strain rate, current axial strain and current deviator stress, and the models were developed to predict the deviator stress in the soil (model output) related to an increment of axial strain. 
The deviatoric stress and axial strain were updated incrementally through the training and testing stages based on output of the model at the end of each increment.

Table 2. The Input and output parameters used for developing the EPR model.

\begin{tabular}{|llc|}
\hline Type & Contributing parameters & Range \\
\hline Input & Temperature $(T)$ & -0.5 to $-11^{\circ} \mathrm{C}$ \\
& Confining pressure $\left(\sigma_{3}\right)$ & 0 to $800 \mathrm{kPa}$ \\
& Strain rate $(\dot{\varepsilon})$ & 0.1 to $2 \mathrm{~mm} / \mathrm{min}$ \\
& Axial strain $\left(\varepsilon_{y}\right)$ & 0 to $10 \%$ \\
& Axial strain increment $\left(\Delta \varepsilon_{y}\right)$ & 0.1 to $0.4 \%$ \\
& Devatoric stress $(q)$ & 0 to $12500 \mathrm{kPa}$ \\
& Devatoric stress for next increment $\left(\boldsymbol{q}_{\boldsymbol{i}+\mathbf{1}}\right)$ & 0 to $12500 \mathrm{kPa}$ \\
\hline
\end{tabular}

353

In the EPR settings, the number of terms was set to 15 and the exponents were set to be in the

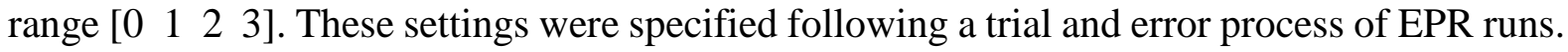
Before running the EPR all the datasets were randomly shuffled to ensure that the obtained EPR model was not biased towards a particular part of the training data. To reduce the required time for EPR training, duplicated data were removed. These steps were implemented through a code written in Matlab in order to simplify the training and reduce the time required for analysis. The best EPR model was selected according to the highest $C o D$ (which was $99.88 \%$ ) as:

$$
\boldsymbol{q}_{\boldsymbol{i}+1}=1.1053 q+154078.5 \Delta \varepsilon_{y}-477650.84 T \Delta \varepsilon_{y}^{2}-994036.26 \sigma_{3} T \Delta \varepsilon_{y}^{3}
$$

$$
-27993.26 \varepsilon_{y}-1.449 \varepsilon_{y} q+12415.7 \dot{\varepsilon} \varepsilon_{y}+242790.28 \varepsilon_{y}^{2}
$$$$
-4446986.22 \Delta \varepsilon_{y} \dot{\varepsilon} \varepsilon_{y}^{2}-2784857.5 \Delta \varepsilon_{y} \dot{\varepsilon} T \varepsilon_{y}^{2}+57959.6 T \varepsilon_{y}^{3}
$$

$$
-0.0817 \sigma_{3} \dot{\varepsilon} q^{2} \Delta \varepsilon_{y}^{3}-34.09
$$


367 (equation 6) together with the actual experimental data used for the training process. It can be

368 clearly seen that the proposed EPR model was able to extract the behavior of the frozen soil

369 under different temperatures, strain rates and confining pressures with excellent accuracy.

370

371

372

373

374

375

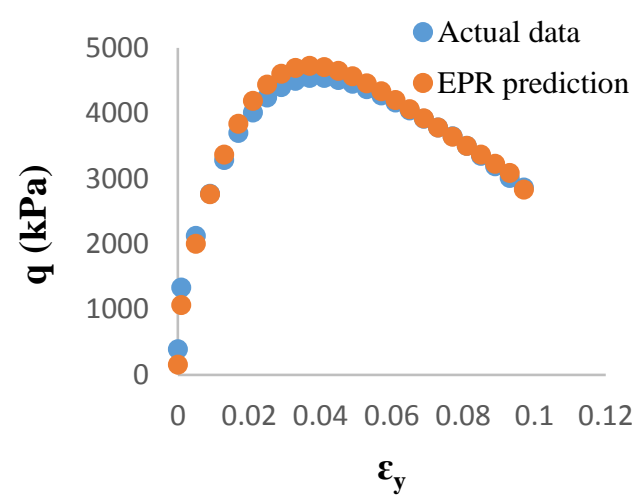

(a)

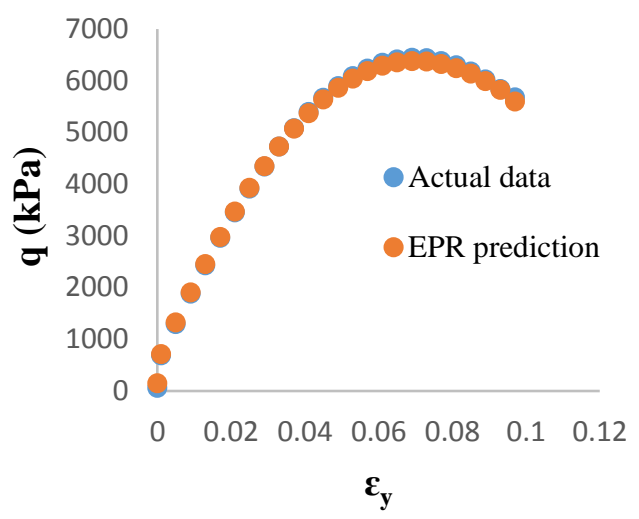

(b)

376

377

378

379

380

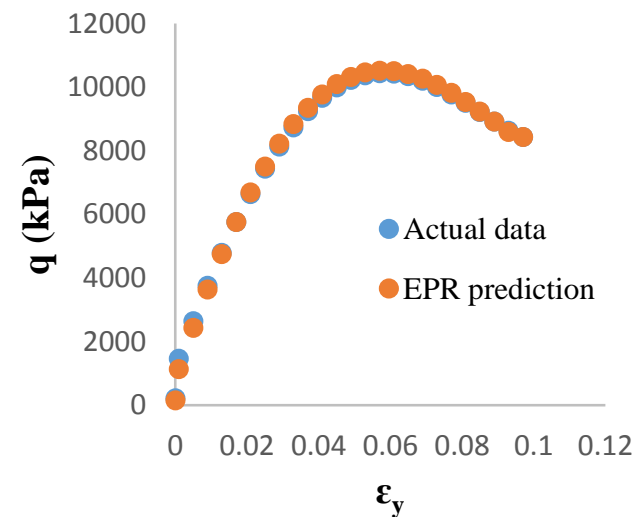

(c)

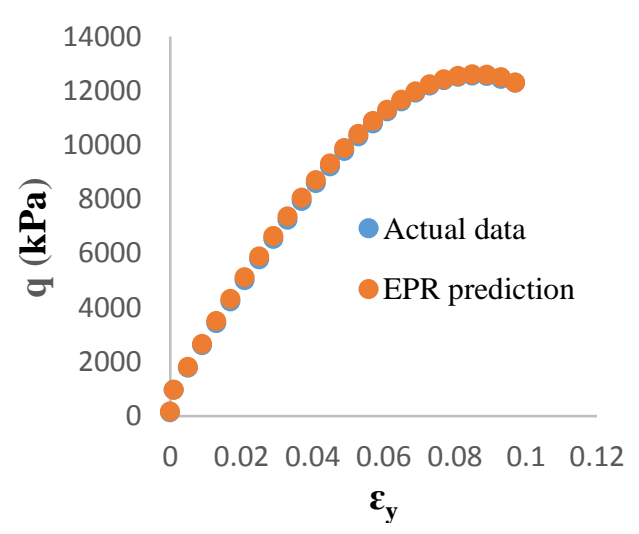

(d)

Figure 5. Comparison between the EPR model predictions and the experimental data for different confining pressures, temperatures and strain rates: (a) $100 \mathrm{kPa},-3{ }^{\circ} \mathrm{C}$ and $0.2 \mathrm{~mm} / \mathrm{min}$, (b) $50 \mathrm{kPa},-5^{\circ} \mathrm{C}$ and 0.5 $\mathrm{mm} / \mathrm{min}$, (c) $800 \mathrm{kPa},-5^{\circ} \mathrm{C}$ and $1.0 \mathrm{~mm} / \mathrm{min}$, (d) $200 \mathrm{kPa},-11^{\circ} \mathrm{C}$ and $1.0 \mathrm{~mm} / \mathrm{min}$. 
386 Moreover, to verify the generalization capability of the developed EPR model, the 387 experimental results are compared with the EPR model predictions for the unseen (testing) data

388 in Figure 6. The results show that the model is able to extend the learning and predict the 389 behavior of the frozen soil under different temperatures, strain rates and confining pressures 390 with very high accuracy.

391

392

393

394

395

396

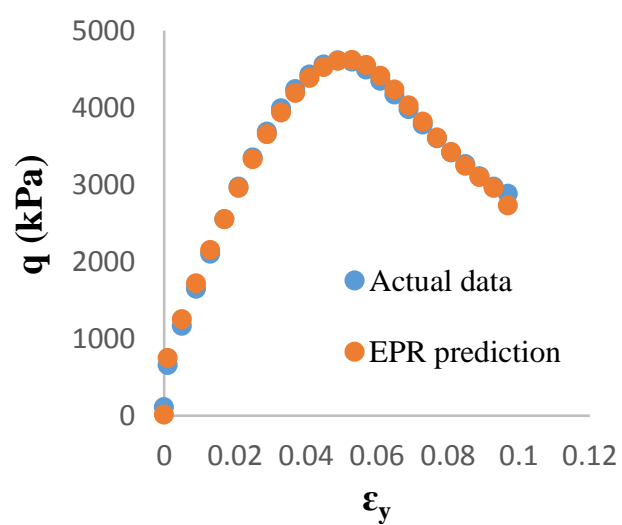

(a)

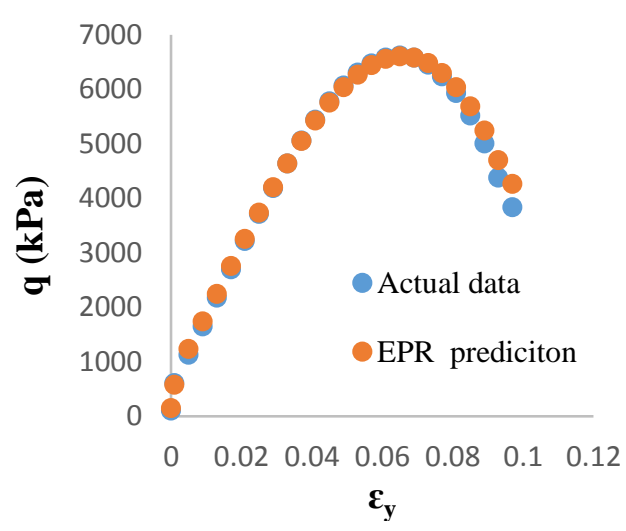

(b)

397

398

399

400

401

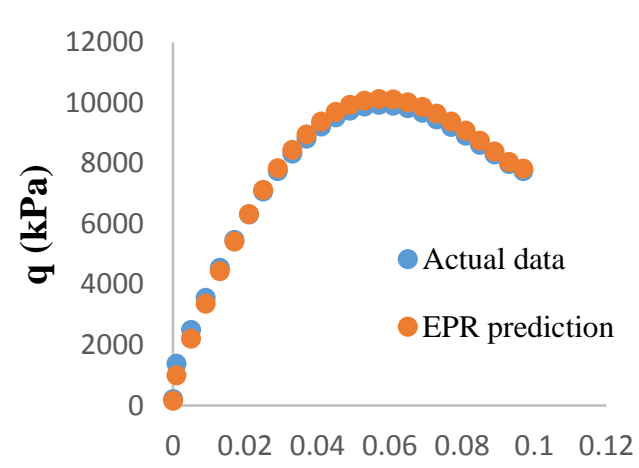

(c)

$\varepsilon_{\mathrm{y}}$

402

403

Figure 6 Comparison between the EPR model predictions and the (unseen) experimental data for different confining pressures, temperatures and strain rates: (a) $0 \mathrm{kPa},-5^{\circ} \mathrm{C}$ and $0.2 \mathrm{~mm} / \mathrm{min}$, (b) $100 \mathrm{kPa},-2{ }^{\circ} \mathrm{C}$ and $1 \mathrm{~mm} / \mathrm{min}$, (c) $400 \mathrm{kPa},-5^{\circ} \mathrm{C}$ and $1.0 \mathrm{~mm} / \mathrm{min}$. 


\section{Predicting the entire stress-strain curve using the EPR model}

408

409

410

411

412

413

414

415

416

417

418

419

422

423

424

425

426

427

2

Further to the model validation presented in section (4), the EPR model was utilized to predict the entire stress-strain curve in the $q: \varepsilon_{y}$ space incrementally, point by point. The results from various sets of unseen (testing) data were used to measure the ability of the developed model to predict the behavior of the frozen soil, point by point, through the entire stress-strain curve. For each experiment, the magnitudes of temperature, strain rate and confining pressure were kept constant and the other parameters were updated incrementally based on the axial strain increment. Figure 7 shows the proposed procedure to update the input variables and build the whole stress-strain curve for the shearing stage of a triaxial experiment. Starting the procedure with zero axial strain and zero deviator stress (representing the starting point of the shearing stage) and using prescribed axial strain increment, the values of the deviator stress $q_{i+1}$ are calculated using the developed EPR model (Ahangar-Asr et al., 2015; Faramarzi et al., 2012). For the next increment, the values of axial strain $\left(\varepsilon_{y}\right)$ and deviator stress $(q)$ are updated as:

$$
q_{i}=q_{i+1}
$$

$$
\varepsilon_{y, i}=\varepsilon_{y, i}+\Delta \varepsilon_{y}
$$

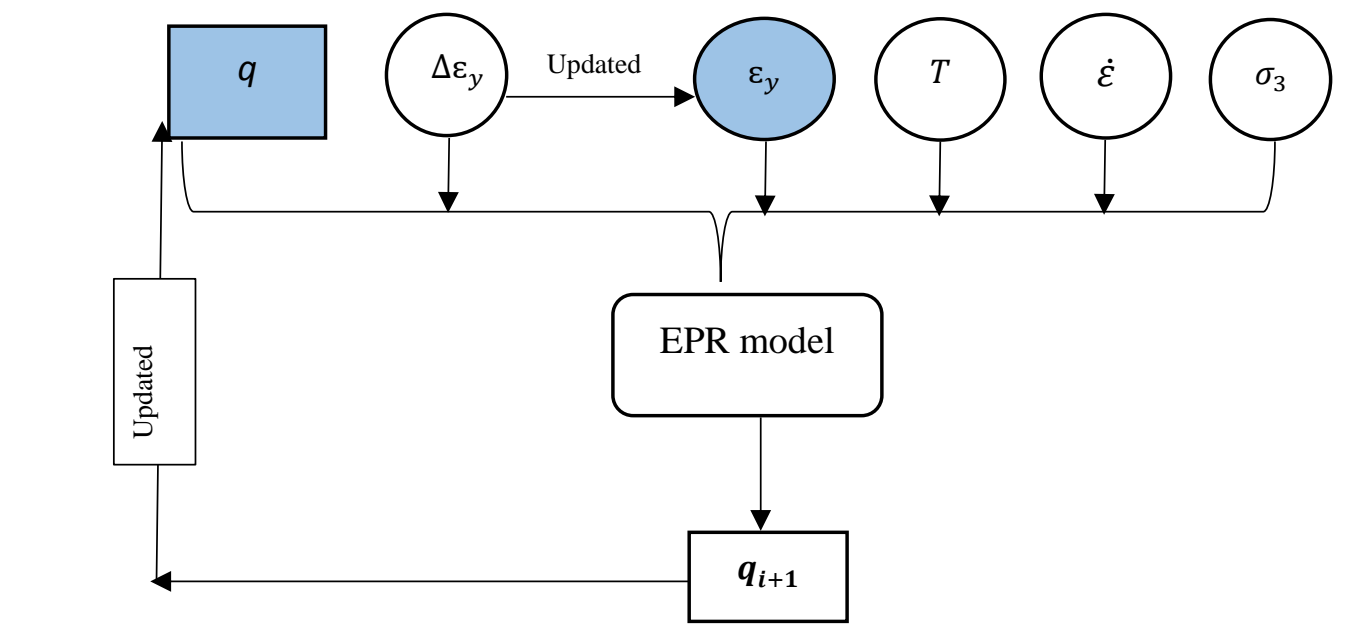

Figure 7. Procedure for predicting the entire stress-strain curve. 
429 In this way, the next point on the axial strain - deviator stress curve is predicted. This algorithm 430 was applied until all the points on the curve were predicted. Figure 8 shows the comparison 431 between the three stress-strain curves predicted (point by point) by the EPR model and the 432 experimental data. The results show very good agreement with the experimental results. The 433 key point of such EPR model validation is that, while the errors were accumulated at every 434 single point during the predictions, the entire curve was predicted very accurately. This is a 435 strong testament of the robustness of the proposed EPR model in capturing and representing 436 the real behavior of the frozen soil.

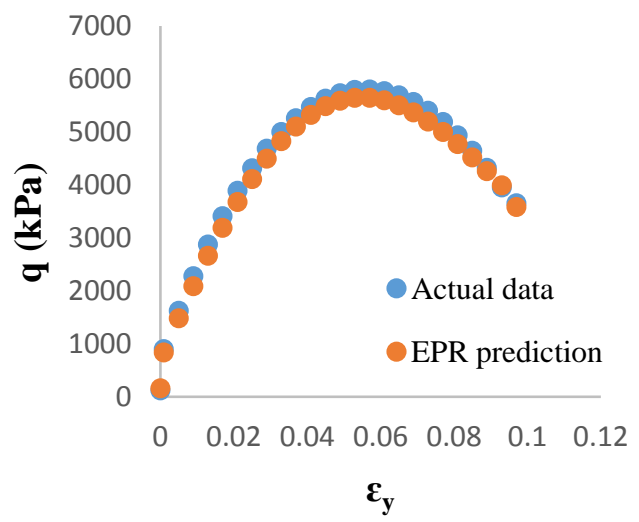

(a)

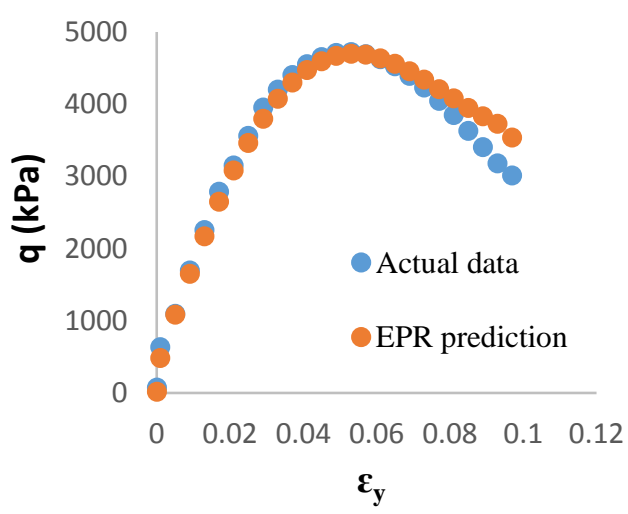

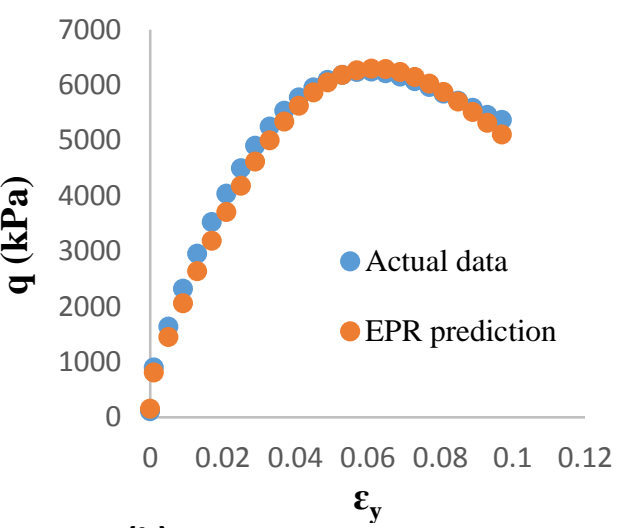

(b)

(c)

Figure 8. Comparison between the EPR model prediction (point by point) and the experimental data for confining pressures, temperatures and strain rates of (a) $0 \mathrm{kPa},-9{ }^{\circ} \mathrm{C}$ and $0.2 \mathrm{~mm} / \mathrm{min}$, (b) $50 \mathrm{kPa},-4{ }^{\circ} \mathrm{C}$ and $0.5 \mathrm{~mm} / \mathrm{min}$, (c) $200 \mathrm{kPa},-3{ }^{\circ} \mathrm{C}$ and $0.2 \mathrm{~mm} / \mathrm{min}$. 


\section{Sensitivity analysis}

451 A sensitivity analysis was conducted on the sets of validation (unseen) data. In this analysis, 452 changes were applied to the values of one selected input variable (within its maximum and 453 minimum range) while other input variables were fixed to their mean values. The analysis 454 included the effects of changes in confining pressure, temperature and strain rate on the 455 deviator stress - axial strain curve. Figures 9-11 show the effect of each input parameter on the 456 soil behavior. It can be seen that, as expected, decrease in temperature results in increase in the 457 deviator stress. Any increase in the confining pressure or strain rate would cause an increase in 458 the deviator stress. These results are expected and consistent with the trends noticed in the experimental tests. The results of the sensitivity analysis indicate that the EPR model has been able to extract and correctly predict the patterns of mechanical behavior of the frozen soil.

461

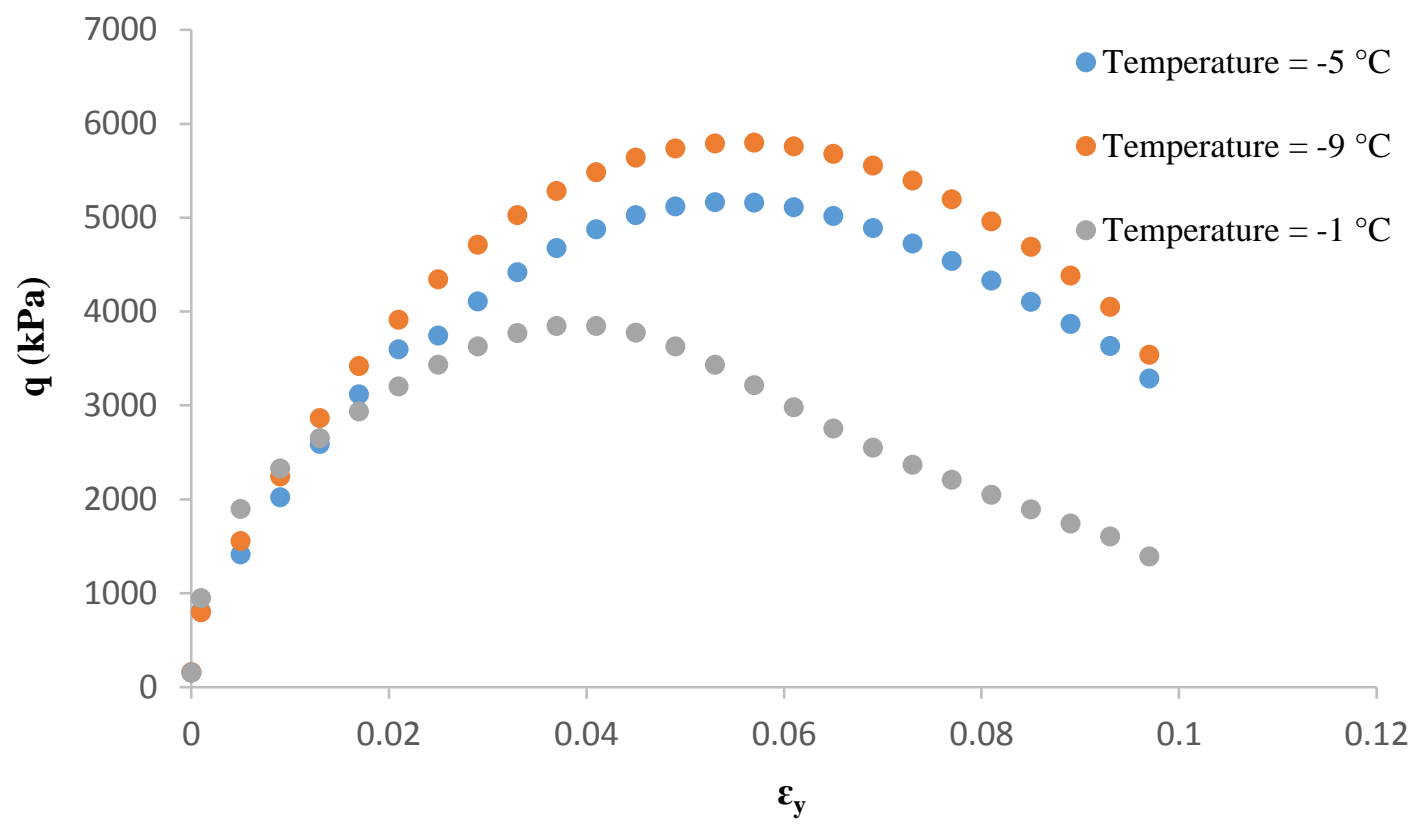

Figure 9. Effect of change in temperature on the behaviour of the frozen soil. 


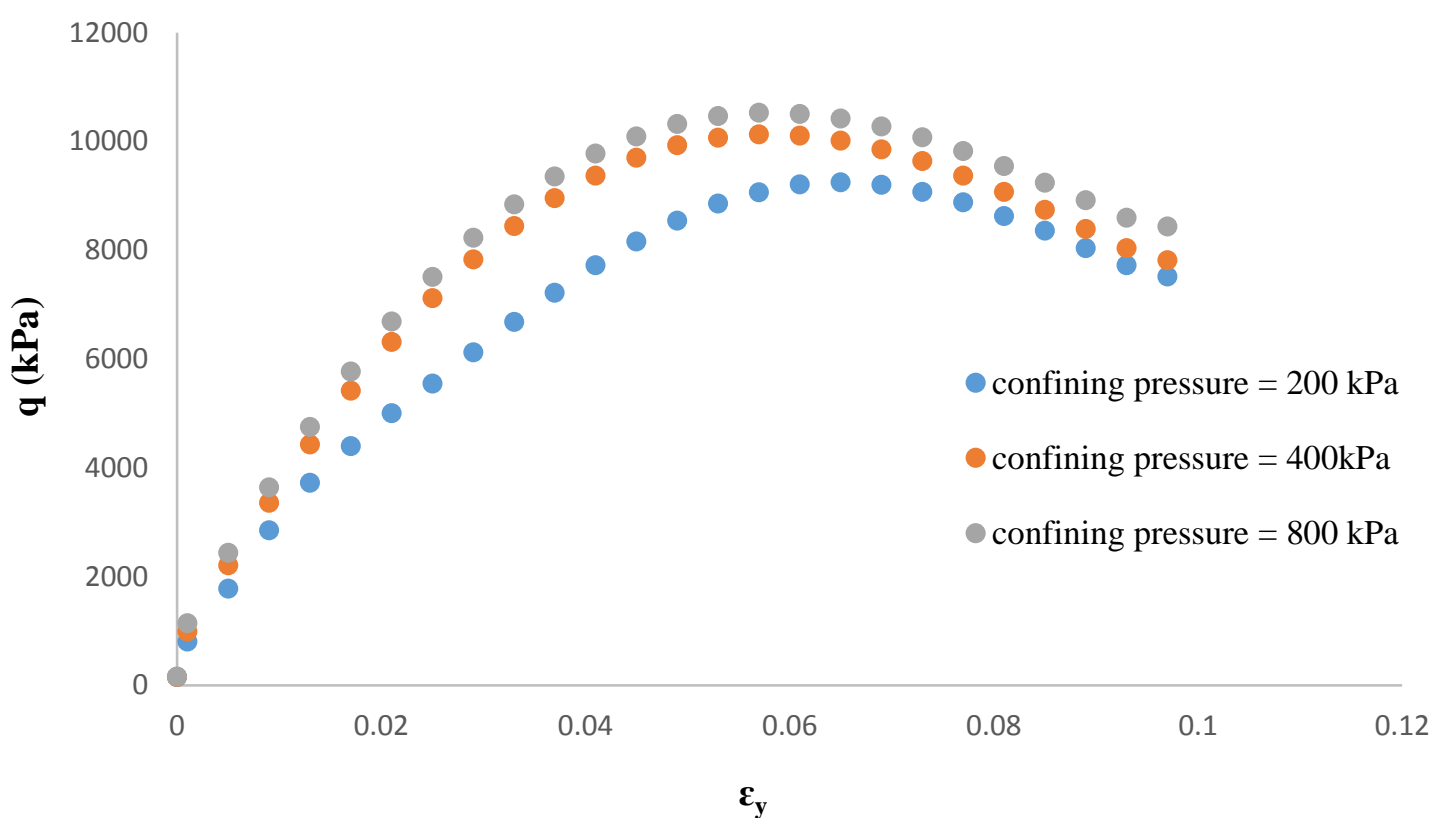

Figure 10. Effect of change in confining pressure on the behaviour of the frozen soil.

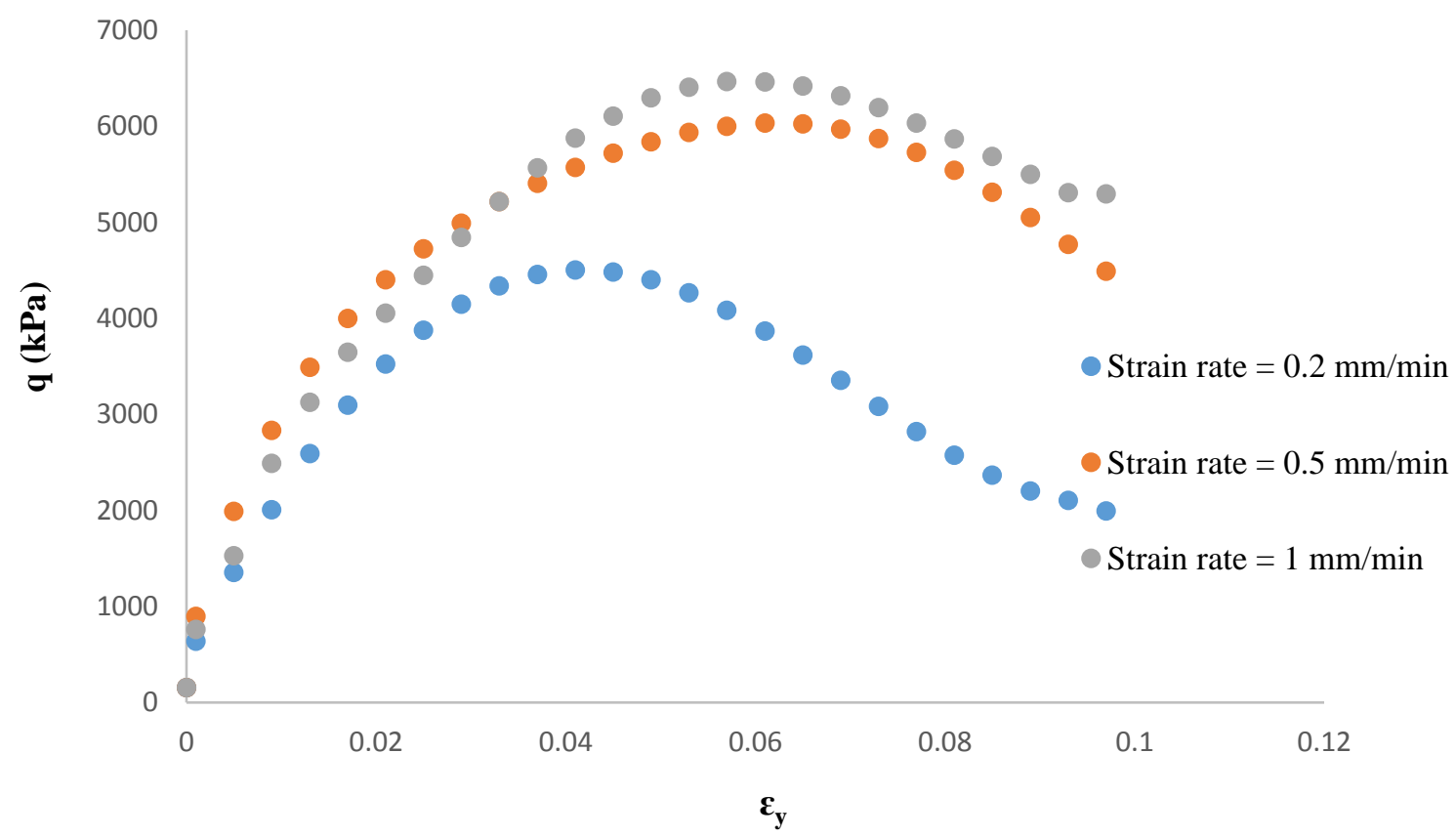

Figure 11. Effect of change in strain rate on the behaviour of the frozen soil. 


\section{Discussion and conclusion}

474 The conventional approach to represent the mechanical behaviour of frozen soils requires

475 special equipment and environment which could be expensive, time consuming and not 476 available in all scenarios. In addition, the behaviour of such soils is very complex because of 477 the multi-phase nature of the mixture. In this paper, a comprehensive set of experimental data 478 from unconsolidated undrained (UU) triaxial tests on a frozen sandy soil were used to develop a model, using evolutionary polynomial regression (EPR), to predict the shear behavior of a frozen soil. The model considers the effects of temperature, confining pressure and strain rate on the soil behavior. The main advantage of using EPR is that it provides a unified approach to material modeling. It can also provide an explicit and well-structured model representing the behavior of the material. EPR has several advantages over other types of data mining tools such as neural network. It is able to extract simply the complex nonlinear behavior of different materials by feeding it with large amount of data.

The methodology of using EPR-based model to describe the material behavior has been verified by comparing the model predictions with the actual data and applying it on sets of unseen data. The results showed the ability of the proposed model in capturing and representing the complex behavior of frozen soils. Furthermore, predicting the entire stress-strain curve (point by point) was presented successfully as another verification of the capabilities of the developed model. A parametric analysis was introduced to assess the sensitivity of the developed EPR model to variations of the individual variables including temperature, confining pressure and strain rate. The results showed the EPR model is able to extract and predict the effect of each parameter on the entire shear-stress curve of frozen soil. It should be noted that, like other data mining techniques, a trained EPR model may be unable to accurately predict the material behaviour outside the range of the training data. 
In such cases, the predicted results should be treated with caution. In practice, the developed model can be used to predict the response of frozen ground in projects involving ground freezing. The model will provide a better insight into the behaviour of frozen soils in engineering applications. The developed model can be implemented in numerical analysis such as finite element method. The incorporation of the developed EPR model into finite element analysis is the subject of current research.

\section{References}

Ahangar-Asr, A.., Faramarzi, A.., Javadi, A.A., 2011. Modelling Mechanical Behaviour of Rubber Concrete Using Evolutionary Polynomial Regression. Int. J. Comput. Eng. 28(4), 492-507.

Ahangar-Asr, A., Javadi, A.A., Khalili, N., 2015. An evolutionary approach to modelling the thermomechanical behaviour of unsaturated soils. Int. J. Numer. Anal. Methods Geomech. 39, $539-557$.

Alangar-Asr;, Javadi, A.A., 2011. Modeling soil-water characteristic curve using EPR Modeling characteristic curve using EPR. Unsaturated Soils Theory Pract. 2011 379-383.

Alani, A.M., Faramarzi, A., 2014. An evolutionary approach to modelling concrete degradation due to sulphuric acid attack. Appl. Soft Comput. J. 24, 985-993. doi:10.1016/j.asoc.2014.08.044

Chamberlain, E.J., 1981. Overconsolidation effects of ground freezing. Eng. Geol. 18, 97-110.

Czurda, K. A., \& Hohmann, M., 1997. Freezing effect on shear strength of clayey soils. Appl. Clay Sci. 12(1), 165-187.

D2487, A.S., 2007. Standard practice for classification of soils for engineering purposes (unified soil classification system). ASTM Int. West Conshohocken, PA.

D4083-89, A., 2016. Standard Practice for Description of Frozen Soils (Visual-Manual Procedure). ASTM Int. West Conshohocken, PA.

Da Re, G., Germaine, J. T., \& Ladd, C.C., 2003. Triaxial testing of frozen sand: Equipment and example results. J. cold Reg. Eng. 17(3), 90-118. 
Doglioni, A., Giustolisi, O., Savic, D.A., Webb, B.W., 2008. An investigation on stream temperature analysis based on evolutionary computing. Hydrol. Process. 22(3), 315-326.

Esmaeili-falak, M., Katebi, H., Javadi, A., 2017. Experimental Study of the Mechanical Behavior of Frozen Soils - A Case Study of Tabriz Subway. Period. Polytech. Civ. Eng. 1-9.

Faramarzi, A., Javadi, A.A., Alani, A.M., 2012. EPR-based material modelling of soils considering volume changes. Comput. Geosci. 48, 73-85. doi:10.1016/j.cageo.2012.05.015

Giustolisi, O., Savic, D.A., 2009. Advances in data-driven analyses and modelling using EPRMOGA. J. Hydroinformatics 11, 225-236. doi:10.2166/hydro.2009.017

Giustolisi, O., Savic, D.A., 2006. A symbolic data-driven technique based on evolutionary polynomial regression. J. Hydroinformatics 8, 207-222. doi:10.2166/hydro.2006.020

Harris, J.S., 1995. Ground Freezing in Practice. Thomas Telford, London., Harris, J. S. 1995. Ground Freezing in Practice. Thomas Telford, London.

Jahed Armaghani, D., Tonnizam Mohamad, E., Momeni, E., Narayanasamy, M.S., Mohd Amin, M.F., 2015. An adaptive neuro-fuzzy inference system for predicting unconfined compressive strength and Young's modulus: a study on Main Range granite. Bull. Eng. Geol. Environ. 74, 13011319. doi:10.1007/s10064-014-0687-4

Javadi, A.A., Ahangar-Asr, A., Johari, A., Faramarzi, A., Toll, D., 2012. Modelling stress-strain and volume change behaviour of unsaturated soils using an evolutionary based data mining technique, an incremental approach. Eng. Appl. Artif. Intell. 25, 926-933. doi:10.1016/j.engappai.2012.03.006

Johansson, T., 2009. Artificial Ground Freezingin Clayey Soils: Laboratory and Field Studies of Deformations during Thawing at the Bothnia Line. Royal Institutie of Technology, Stocholm, Sweeden.

Lackner, R., Amon, A., Lagger, H., 2005. Artificial Ground Freezing of Fully Saturated Soil: Thermal Problem. J. Eng. Mech. 131(2), 211-220.

Lai, Y., Liao, M., Hu, K., 2016. A constitutive model of frozen saline sandy soil based on energy dissipation theory. Int. J. Plast. 78, 84-113. doi:10.1016/j.ijplas.2015.10.008

Li, S., Lai, Y., Zhang, M., Zhang, S., 2006. Minimum ground pre-freezing time before excavation of Guangzhou subway tunnel. Cold Reg. Sci. Technol. 46, 181-191. doi:10.1016/j.coldregions.2006.09.001 
Ma, W., Chang, X., 2002. Analyses of strength and deformation of an artificially frozen soil wall in underground engineering. Cold Reg. Sci. Technol. 34(1), 11-17.

Millar, D.L., 2008. Parallel Distributed Processing In Rock Engineering Systems. PhD thesis, Imperial College of Science, Technology \& Medicine, London.

Momeni, E., Nazir, R., Armaghani, D.J., Maizir, H., 2014. Prediction of pile bearing capacity using a hybrid genetic algorithm-based ANN. Measurment 57, 122-131. doi:10.1016/j.measurement.2014.08.007

Monjezi, M., Rezaei, M., 2011. Developing a new fuzzy model to predict burden from rock geomechanical properties. Expert Syst. Appl. 38, 9266-9273. doi:10.1016/j.eswa.2011.01.029

Pimentel, E., Anagnostou, G., 2010. Large-scale physical model for simulation of artificial ground freezing with seepage flow. 7th Int. Conf. Phys. Model. Geotech. 28th June - 1st July, Zurich, Switzerland, CRC Press. Zurich,2010 379-382.

Rezania;, M., Javadi;, A., Orazio Giustolisi, 2008. An Evolutionary-Based Data Mining Technique for Assessment of Civil Engineering Systems. Eng. Comput. Int. J. Comput. aided Eng. Softw. 25, $500-517$.

Rotta Loria, A.F., Frigo, B., Chiaia, B., 2017. A non-linear constitutive model for describing the mechanical behaviour of frozen ground and permafrost. Cold Reg. Sci. Technol. 133, 63-69. doi:10.1016/j.coldregions.2016.10.010

Wang, S., Qi, J., Yu, F., \& Liu, F., 2016. A novel modeling of settlement of foundations in permafrost regions. Geomech. Eng. 10(2), 225-245.

Xu, X., Lai, Y., Dong, Y., Qi, J., 2011. Laboratory investigation on strength and deformation characteristics of ice-saturated frozen sandy soil. Cold Reg. Sci. Technol. 69, 98-104. doi:10.1016/j.coldregions.2011.07.005

Xu, X., Wang, Y., Yin, Z., Zhang, H., 2017. Effect of temperature and strain rate on mechanical characteristics and constitutive model of frozen Helin loess. Cold Reg. Sci. Technol. 136, 44-51. doi:10.1016/j.coldregions.2017.01.010

Yang, Y., Feng, G., Yuanming, L., Hongmei, C., 2016. Experimental and theoretical investigations on the mechanical behaviors of frozen silt. Cold Reg. Sci. Technol. 130, 59-65. 
Yang, Y., Lai, Y., Dong, Y., Li, S., 2010. The strength criterion and elastoplastic constitutive model of frozen soil under high con fi ning pressures. Cold Reg. Sci. Technol. 60, 154-160. doi:10.1016/j.coldregions.2009.09.001

Zhang, S., Lai, Y., Sun, Z., Gao, Z., 2007. Volumetric strain and strength behavior of frozen soils under confinement. Cold Reg. Sci. Technol. 47, 263-270. doi:10.1016/j.coldregions.2006.10.001

Zhao, X., Zhou, G., Chen, G., 2013a. Triaxial compression strength for artificial frozen clay with thermal gradient. J. Cent. south Univ. 20, 218-225. doi:10.1007/s11771-013-1479-x

Zhao, X., Zhou, G., Wang, J., 2013b. Deformation and strength behaviors of frozen clay with thermal gradient under uniaxial compression. Tunn. Undergr. Sp. Technol. Inc. Trenchless Technol. Res. 38, 550-558. doi:10.1016/j.tust.2013.09.003

Ziegler, M., Schüller, R., \& Mottaghy, D., 2013. Numerical simulation of energy consumption of artificial ground freezing applications subject to water seepage, in: In Proceedings of the 18th International Conference on Soil Mechanics and Geotechnical Engineering: The Academia and Practice of Geotechnical Engineering, Paris, France. pp. 2985-2988.

Ziegler, M., Baier, C., Aulbach, B., 2009. Simplified phase change model for artificially frozen ground subject to water seepage. Proc. 17th Int. Conf. Soil Mech. Geotech. Eng. Acad. Pract. Geotech. Eng. Alexandria, Egypt, 5-9 Oct. 2009. 562-565. doi:10.3233/978-1-60750-031-5-562 